\title{
Educação, família e trabalho: a igualdade de género numa perspetiva de (re) conciliação
}

\author{
Benilde Moreira \\ Departamento de Ciências Sociais, Escola Superior de Educação, Bragança
}

\begin{abstract}
Resumo
A educação, a família e o trabalho são polos sociais geradores de tensões que se repercutem nas medidas da igualdade de género. As políticas educacionais, de relações familiares e a regulação laboral projetam, entre si, construções sociais dos papéis do género que marcam o homem e a mulher numa posição desvantajosa. $\mathrm{O}$ princípio de justiça transicional de género deriva de um processo de conceptualização que pretende demonstrar a possibilidade de diminuir o intervalo de género que subsiste entre homem e mulher. O dever positivo de género é um imperativo categórico para todos os intervenientes sociais.
\end{abstract}

Palavras-chave: igualdade de género, justiça transicional, integração de género, políticas sociais.

\section{Educação, família e trabalho: tensões emergentes do género}

A educação, a família e o trabalho são unidades funcionais da sociedade que interagem como polos dinamizadores de políticas de inclusão e paridade. As tensões que daqui resultam provocam desequilíbrios sociais nas relações educacionais, nas ligações familiares e no envolvimento laboral. O presente artigo identifica quais são as tensões na educação, na família e no trabalho com a finalidade de revelar a persistência de um intervalo de género, penalizador da efetivação das políticas legais da igualdade de género. A minha proposta de reconciliação das tensões emergentes do género pretende incentivar a adoção de "medidas que promovam a conciliação trabalho-família e a igualdade de género..." como um “...fator de competitividade, coesão social, cidadania e qualidade de vida.” Guerreiro (2010). O desafio questiona se esta nova geração de direitos de igualdade de género tem capacidade de ultrapassar as barreiras que ainda subsistem nas vidas de homens e mulheres.

O objetivo da utilização do conceito de igualdade de género, na área educacional visa questionar a divisão tradicional dos papéis e dos estereótipos do género. As políticas educacionais tentam perceber como aumentar o número de mulheres em órgãos diretivos, entender as escolhas das áreas formativas em função do género, estudar os resultados de aproveitamento entre rapazes e raparigas ou desconstruir o lado da feminização da profissão.

Os estereótipos formam-se desde a infância. Paechter (2000) refere-se a pressupostos explícitos e implícitos. Disciplinas como as ciências, matemática ou tecnologia estão associados ao sexo masculino enquanto disciplinas como línguas, literatura, história encontram-se conotadas com o sexo feminino. $\mathrm{O}$ autor identifica este lado, mais explícito do estereótipo mas alega que existe um padrão oculto. As escolas são centros de relações sociais em sala de aula, no recreio, nos grupos de amizade, nas relações com os professores e alunos que acabam por contribuir, do mesmo modo, para a formação do estereótipo.

No campo do ensino Butler (1990) defende, por exemplo, que a posição do género centra-se mais sobre a forma como os alunos se envolvem ativamente na sua formação e aquisição de características na relação que estabelecem uns com os outros. A forma como se posicionam é influenciada pela proveniência do meio social estratificado. Ou seja, o exercício da liberdade de escolha não é feito da mesma forma atendendo ao meio social onde se inserem os rapazes e as raparigas. Sammons (1995) defende que à partida estão mais bem posicionados aqueles que têm famílias com melhores rendimentos ou pais mais instruídos. Segundo Neimanis (2001) o que se pretende alcançar é uma igualdade de género nas taxas de inscrição nas escolas, na conclusão da escolaridade, na estruturação idêntica da profissão de docente e na inclusão do tema estereótipos de género nos currículos e formação dos docentes. A inclusão deste tema é de suma importância no estudo sobre as diferenças entre os sexos porque "os padrões observados de diferenças entre sexos varia frequentemente, em função das culturas, ao longo do tempo em cada cultura, e também ao longo do desenvolvimento na infância.” (Arnot et all. 1999). O currículo escolar acaba por transmitir "uma divisão do trabalho com base no sexo dentro do processo social de escolarização” (Humm 1989).

Loots e Walker (2015) propõem a aplicação da perspetiva das capacidades humanas, idealizada por Martha Nussbaum (2000). Para uma igualdade de género nas políticas educacionais há que proceder a mudanças estruturais nos estabelecimentos de ensino de forma a garantir a expansão das oportunidades, associadas ao desenvolvimento dos estudantes. O foco é a sua individualidade, as suas capacidades humanas e o modo de as colocar em funcionamento. De acordo com Robeyns (2008) existe por trás uma perspetiva de ética individual. Por mais estudos realizados, quer no plano individual quer no plano das estruturas sociais, o que interessa, em última análise, é a preocupação moral de oferecer bem-estar ao indivíduo.

A educação não pode ser o único e decisivo instrumento na mudança das construções sociais de género. A família constitui o polo centralizador das primeiras vivências sociais, determinante nas escolhas promovidas na infância. Wood (1987) considerou que é irresponsável considerar a educação como instrumento principal para a obtenção de igualdade de oportunidades na vida. As influências 
familiares são provenientes de duas plataformas: a origem social e o padrão familiar. Ambas contribuem para a construção de uma visão sobre o desempenho do papel masculino e do papel feminino bem como para a definição de diferentes pontos de partida entre os sexos. Na ordem familiar contemporânea há, ainda, que considerar a crise de masculinidade (Wall, Aboim e Cunha, 2010) onde está em causa uma identidade, tradicionalmente, paternalista e, agora, sujeita a uma adaptação de mudança de mentalidades que deu origem à formação de novos padrões familiares.

A linguagem jurídica adotou uma estrutura neutral de género. Quer dizer que os direitos consagrados podem ser exercidos, indiferentemente do género. A regulação jurídica das relações familiares, sobretudo no que se refere aos direitos de personalidade, à igualdade e não discriminação e à parentalidade traduzem o que chamo de princípio jus-familiar revelado pela via constitucional, pela área civil e pelo campo laboral. Há um reconhecimento evidente da unidade familiar como "elemento fundamental da sociedade".

Se o princípio jus-familiar norteia a igualdade de posições entre os membros do agregado familiar, então, porque persistem diferenças de papéis sociais? Recupere-se o que foi dito, acima, sobre as capacidades humanas. A família é o centro, por excelência do exercício da individualidade. Contudo, a liberdade de escolha, subjacente à individualidade, é constrangida pela posição social e pelo padrão familiar. Ainda que as políticas públicas disponham de estruturas financeiras e humanas - o que não é o caso não há instrumento que garanta que a família fará uso delas, as ignore ou, até mesmo, as sacrifique em benefício do agregado familiar.

A alteração do padrão familiar fez, também, emergir tensões. O conceito de "família moderna" não é novo. Já Lamanna (2001) sobre a visão de Durkheim acerca da família e Parsons (1995) afirmam a preocupação do estatuto social que a família ocupa na sociedade, como uma célula onde se constroem e transmitem ideias, valores, costumes e distribuição de papéis. Seguindo esta posição Aboim (2006 e 2007) e Torres (2001) argumentam que a diferenciação dos papéis de género através de normas que pretendem a paridade entre homens e mulheres coloca desafios aos antigos padrões patriarcais.

Wall (2005) num trabalho sobre inquéritos quantitativos das Famílias no Portugal Contemporâneo identificou um modelo que designa de "fusão conjugal”, padrão familiar onde é estabelecida uma aliança conjugal. A sociedade Ocidental integra as questões da igualdade de tratamento e aceita-as, contudo, subsistem os estereótipos. Aboim (2010) fala mesmo da alteração da visão masculina de "provedor autoritário" para a de "providenciador afetuoso" que participa em alguns cuidados na vida doméstica e aceita que a mulher apoie na função de ganha-pão. Não obstante é a mulher que é entendida como a principal organizadora dos afazeres domésticos e prestação de cuidados à família. Neste caso a desigualdade tende a sublevar-se de forma mais subtil. A envolvência do homem na esfera privada é de complementaridade ao invés de resultar de um desapego natural das construções sociais dos papéis de género. Neste dilema o uso do tempo e a prestação de cuidados à família são os pesos-pesados das pressões familiares. Vigerust (2000) afirma que a base para a conciliação entre a família e o trabalho impõe, sob o ponto de vista legal, uma obrigação ao empregador de facilitador de tempo. Na mesma linha defendo que o conteúdo do princípio jus-familiar, do ordenamento jurídico português, impõe o dever positivo de género. A entidade empregadora que continua a valorar o fator "presencismo" (Guerreiro, 2010) deve assumir um papel de simplificador do uso do tempo reorganizando a estrutura laboral, flexibilizando os tempos de trabalho e criando políticas amigas da família.

$\mathrm{O}$ aspeto formal da igualdade de género encontra-se bem protegido quer pela Constituição da República Portuguesa quer pelo Código do Trabalho. O mesmo já não se pode afirmar relativamente ao aspeto substantivo da igualdade, avaliada em função dos resultados obtidos por políticas paritárias. Neste sentido, em 1995, foi adotado, em Pequim, o conceito de "gender mainstreaming", por prestigiadas organizações internacionais, que levaram os governos a introduzir uma perspetiva de género em todas as políticas públicas. Não obstante, decorridos 20 anos as Nações Unidas constatam a persistência do "gender gap”, facto que não é pueril.

O intervalo de género persiste, a meu ver, por dois aspetos prementes: (1) a fraca litigância no domínio da conciliação família e trabalho e (2) o comportamento do tecido empresarial.

Num levantamento sobre 22 anos de decisões judiciais na área da igualdade laboral em razão do sexo (CITE, 2006) apurou-se que "os tribunais no nosso País não apreciaram as situações que lhes foram submetidas num contexto de discriminação directa ou indirecta em função do género.” Também referem que na aplicação da lei, os tribunais "ignoraram a emissão de pareceres em matéria de igualdade no trabalho e no emprego" que são emitidos pela CITE. Acrescentam que não atenderam à prática decorrente do direito comunitário sendo, portanto, desconsiderados padrões de aplicação da igualdade, tornando irrelevantes a jurisprudência proveniente da União Europeia. Pela via judicial e de acordo com a visão de McGlyn (2000) os tribunais contribuem para a criação de uma ideologia. Eu acrescento que uma vez disseminada a ideologia jurisprudencial o impacto na vida dos cidadãos é incontornável. Daí a importância de uma maior litigância quanto à conciliação entre vida familiar e vida profissional.

Esta questão não pode ser dissociada do comportamento das organizações empregadoras. O tecido empresarial é, hoje, influenciado pela crise financeira mundial. As repercussões na Europa têm sido nefastas em vários domínios e o mercado tem sofrido mudanças substanciais. O quadro jurídico-laboral foi sendo adaptado ao padrão da competitividade e flexibilidade exigíveis não só às empresas mas, também, aos trabalhadores. O recurso à contratação a prazo tornou-se recorrente e na última década o padrão "flexibilização na margem " (Dornelas et al., 2011) tem caracterizado um recurso predominante ao emprego temporário, mas economicamente dependente, que tem expressão nos falsos recibos verdes, o que acentua a segmentação do mercado e aprofunda as desigualdades sociais. O tecido económico composto, maioritariamente por pequenas e microempresas não se modernizou e as gestões pouco qualificadas mostram reservas ao investimento, formação e contratação de pessoal qualificado. 
O trabalho é o motor de funcionamento e sustento da família. As tensões resultantes do exercício de uma profissão têm implicações na família e na educação na medida em que "a interferência entre o que ocorre nos espaços laboral e doméstico é, em geral, difícil de ser gerido, e os seus reflexos, serão tanto maiores quanto a dedicação a um destes domínios tenda a ser vista como inconciliável...” (Guerreiro, 2006). A realidade portuguesa tem demonstrado que as famílias precisam de dois salários para equilibrar o orçamento doméstico. As diferenças estabelecidas para o papel de cada membro resultam, em grande parte, das decisões familiares influenciadas pelo (des) equilibrio financeiro. Neste sentido Friedman e Greenhaus (2000) defendem que a família e a profissão afetam-se mutuamente. O modelo de "fusão conjugal” onde os papéis dos seus membros interagem com um sentimento de partilha, acaba ferido por constrangimentos impostos pelas entidades empregadoras. Os membros trabalhadores do agregado familiar decidem favorecer a política de "presencismo" das organizações empregadoras que beneficiam a renovação dos vínculos contratuais baseados naquele critério, ao invés de atenderem a requisitos como a produtividade ou competência. O Estado social gere a questão do uso do tempo e da prestação de cuidados à família, contudo, os apoios revelam grandes fragilidades pois as políticas públicas não se enquadram nas necessidades das organizações empregadoras e estas não se compadecem com a necessidade do uso do tempo dos seus trabalhadores para fins pessoais. O estereótipo permanece.

Recorrendo à figura da leveza e do peso do ser, da obra de Kundera, pode dizer-se que a leveza que o trabalho deve representar para a família, por ser a fonte da sua subsistência, torna-se no peso que dificulta a interação social dos membros do agregado familiar. Será, então, que a igualdade de género termina num dogma irresolúvel e devemos conformar-nos com a distância entre os géneros ditada pelos condicionalismos de um mercado capitalizado e consumista? O que proponho como solução dogmática é uma nova conceptualização do princípio de justiça transicional através de um método interpretativo onde subjaz a aplicação do princípio jus-familiar e um modo de atuação que compreende a identificação do intervalo de género, a redistribuição e a restauração.

\section{O princípio de justiça transicional de género: um modelo de (re) conciliação}

A justiça tem sido discutida como valor social, imprescindível na definição de políticas cujo objetivo consiste na diminuição das desigualdades. $\mathrm{O}$ debate sobre a justiça transicional reflete sobre os mecanismos que permitem as sociedades ajustarem-se a um período de desequilíbrio que afetou as suas estruturas sociais. De acordo com o Centro Internacional de Justiça Transicional o conceito "é a resposta à violação sistemática de direitos humanos. Procura reconhecer os direitos das vítimas e promover possibilidades de paz, reconciliação e democracia.” Esta abordagem normativa internacional ganhou contornos muito consensuais por parte da academia, autoridades públicas e organizações internacionais e depressa ganhou relevo nos debates sobre o género. (Fineman e Zinsstag, 2013)
O que se pretende com a utilização do conceito de justiça transicional de género é expor o seu nível de análise sob o ponto de vista micro societário, num plano nacional. Para isso farei recurso de uma metodologia interpretativa do conceito de justiça, do conceito de transição e do dever positivo de género. Para demonstrar a sua aplicação prática defino três etapas: a identificação do intervalo de género, a redistribuição e restauração do estatuto de igualdade.

A justiça, como valor social, surge associada à igualdade e ao papel redistribuidor do Estado. Rawls (1971) e Dworkin (1985) introduziram no debate académico a questão da liberdade como um valor mais importante do que a igualdade. A liberdade está ligada à autonomia do indivíduo e à sua possibilidade de escolha. Este ponto é reforçado quando Dworkin defende que "o governo deve ser neutro" e que deve tratar o individuo com igual preocupação e respeito. Anos mais tarde, autoras como Nussbaum (1999) e Rhode (1989) notam que “o que é necessário é uma visão universal acerca das capacidades humanas...” e que “ esta intenção é o que deve orientar o planeamento de políticas públicas...”. Nussbaum (2000) estabelece uma visão de capacidades humanas centrais que têm uma forte relação com a questão da justiça de género. As habilidades morais de cada indivíduo devem ser exercidas através da sua liberdade de escolha possibilitando, assim, o seu desenvolvimento.

O elenco das capacidades humanas é um valor intrínseco da liberdade de escolha e, portanto, da individualidade e da justiça. Porém, as tensões emergentes da educação, família e trabalho fazem incendeiam a problemática da igualdade substantiva, ou seja, a eficácia das escolhas. É que o exercício da liberdade de escolha é, frequentemente, uma falsa escolha levando a resultados de igualdade enviesados. Veja-se, por exemplo, um caso de conhecimento empírico. Num processo de recrutamento uma mulher, em idade fértil, é livre de responder a questões de natureza pessoal que envolvem a sua vontade - ou não - para ter filhos. E, no entanto, frequentemente dirá que não é um projeto que tenha naquele momento. Na sua resposta a mulher pondera o risco de uma potencial contratação baseada na conceção que as organizações empregadoras colocam no “presencismo” no local de trabalho. Para não colocar em perigo um eventual vínculo laboral, a mulher abdica do exercício da sua verdadeira escolha, que poderá ser trabalhar e, simultaneamente, ter filhos. Logo o exercício das capacidades inerentes encontra-se ferido e não é usado na sua plenitude.

O que defendo na conceção do conceito de justiça transicional de género é o exercício livre da escolha - aqui refiro-me a uma liberdade alheia de ónus sociais. Para tanto é necessário eliminar ou reduzir a desvantagem posicional do género. O homem encontrar-se-á em posição de desvantagem quando é estigmatizado por optar pela partilha de tarefas domésticas na sua vida familiar. A mulher estará numa posição de desvantagem quando opta por gozar a totalidade de uma licença parental em virtude de auferir um rendimento inferior ao do homem, acabando por estagnar a sua carreira. A justiça, para uma integração de género, deve implicar a liberdade e a individualidade na justa medida do seu resultado.

E quanto ao conceito de transição? O aspeto transicional da justiça implica a identificação de uma posição 
desvantajosa do género e, a partir desse momento, surge um imperativo de correção, de transição da desvantagem para a vantagem. Deste modo obtemos a definição de um princípio de justiça transicional de género como aquele que identifica os desequilíbrios, resultantes da construção social, valorativa dos papéis do homem e da mulher, exigindo a sua correção através de um dever imperativo de género baseado quer na legalidade quer na adoção de instrumentos de redistribuição e restauração da posição desvantajosa.

Considero que esta conceção teórica é insuficiente enquanto mecanismo de correção. É imprescindível decalcar o método de aplicação da teoria para a prática. Assim o princípio de justiça transicional de género deve moldar-se em três etapas: (1) a identificação do intervalo de género, (2) a redistribuição e a (3) restauração.

A identificação do intervalo de género assenta na elaboração de planos estratégicos de integração de género. Pode afirmar-se que estes modelos já existem e que o Governo os adota sob a forma de planos nacionais para a igualdade. Porém trata-se de um instrumento com declarações de boas intenções sob a forma de "soft law" e que depressa é esquecido quando sobrevêm crises financeiras como a dos últimos anos. Neste campo defendo o modelo "hard law" que impõe a adoção obrigatória de um plano estratégico, definidor de políticas de integração de género, quer para o setor público quer para o setor privado, com a finalidade de apurar as disparidades entre homem e mulher - o intervalo do género -, determinar os resultados e corrigi-los.

A justiça transicional de género pressupõe, de seguida, a redistribuição. Este passo deriva da constatação de uma tensão gerada na posição de igualdade. Frasier (2002) constatou que "uma das ameaças à justiça social... é resultado de uma ironia histórica: a transição da redistribuição para o reconhecimento está a ocorrer apesar... da aceleração da globalização económica.” Quer a autora dizer que, da mesma forma que surgem "conflitos identitários”, o capitalismo globalizante está “a exacerbar radicalmente as desigualdades económicas.”

A função redistributiva assenta em dois pressupostos: por um lado uma distribuição justa, por outro lado, um reconhecimento mútuo. Na conciliação entre educação, família e trabalho a justiça distributiva verifica-se na questão do uso do tempo e na forma como é empregado, diferentemente, por cada um dos géneros. A envolvência social, onde residem os estereótipos, condiciona o meio como é utilizado o tempo. A redistribuição pode implicar uma nova organização da divisão do trabalho, a reestruturação das necessidades dos recursos humanos ou, mesmo, uma nova conceção de sustentabilidade económica da empresa.

O reconhecimento mútuo implica uma constatação de subordinação do indivíduo a um estatuto de desigualdade, esta derivada das construções sociais do género. É o caso da dupla jornada de trabalho onde a mulher se encontra presa a um paradigma. Em pouco mais de meio século conquistou direitos iguais aos do homem, integrou o mercado de trabalho, adquiriu qualificações, frequenta em maior número os estabelecimentos de ensino e, ainda assim, a sua posição permanece em desvantagem. Na dupla jornada a mulher dedica tempo ao seu trabalho remunerado e, de seguida, a trabalho doméstico não pago. Esta circunstância remete-a para um estatuto de desigualdade. O homem não escapa ao mesmo estatuto. Vejam-se os casos em que pretende assumir maiores responsabilidades familiares. Está condicionado pelo estigma de "providenciador" do sustento familiar e por, normalmente, auferir um maior rendimento. A função redistributiva impõe um reconhecimento mútuo das posições desvantajosas que o homem e a mulher ocupam. Esse reconhecimento deve ser feito por via do estatuto de desigualdade. Os agentes reconhecem mutuamente as raízes que deram origem às disparidades e empenham-se em corrigi-las.

A última etapa de aplicação do princípio de justiça transicional de género diz respeito ao processo de restauração que requer a adoção de medidas corretivas do intervalo de género. Neste ponto recordo a obra de Habermas (1998), Between Facts and Norms, onde o autor justifica a legitimidade do direito e a sua necessidade para o alívio das tensões entre os factos e as normas. O autor defende um modelo de comunicação para justificar a criação de regras jurídicas. O indivíduo deve ter uma plataforma de ação comunicativa através da qual contribui para chegar a um entendimento social mútuo aproximando-se esta postura de um conceito de solidariedade social. Para Habermas existe um ideal de comunicação entendido como um instrumento que vai permitir a formação de um corpo normativo.

O processo de restauração no princípio de justiça transicional de género implica uma comunicação livre de pressões económicas e sociais onde os indivíduos se tratam de forma igual e cooperam para alcançar consensos em matérias de interesse comum. $\mathrm{O}$ processo de restauração exige a interação entre a organização empregadora e os agentes que se encontram definidos no âmbito de um estatuto de desigualdade resultante da sua posição desvantajosa. A nuance de justiça transicional de género tem lugar na fronteira em que os membros de um agregado familiar podem exercer o seu direito à liberdade de escolha, isento de quaisquer constrangimentos sociais. Para tanto as entidades públicas e privadas devem empenhar-se no processo de restauração propondo medidas corretivas que implicam uma transição justa de um estatuto de desigualdade para um reconhecimento justo de uma posição que pretende igualar o ponto de partida para o homem e para a mulher.

\section{Conclusões}

A educação, a família e o trabalho são polos, da unidade social, onde se desenvolvem tensões que problematizam o processo educacional e relacional entre a família e o trabalho.

A conceção teórica e prática que proponho encerra a possibilidade de conciliar essas tensões quer pela via judicial quer pela via não judicial. Na via judicial é importante que a litigância, no domínio da conciliação entre a vida familiar e a vida profissional, ganhe maior impacto. Para tanto deve considerar-se o princípio jus-familiar conduzido pelo dever positivo de género. Por um lado os tribunais, enquanto decisores, contribuem para a construção da ideologia de conciliação entre família e trabalho invocando, sem receio, as normas protetoras da igualdade e 
não discriminação e da parentalidade, nacionais ou internacionais - esta a conceção teórica do princípio de justiça transicional de género. Por outro lado, os tribunais, enquanto entidade pública, são agentes aplicadores das etapas de identificação do intervalo de género, redistribuição e restauração, promovendo e adotando medidas necessárias a uma transição paritária - conceção prática do modelo.

Na via não judicial o envolvimento dos agentes públicos e privados é crucial. O setor público demonstra avanços na implementação da perspetiva de género uma vez que assim determinam as imposições provenientes da União Europeia. O maior défice de empenho com políticas de integração de género para a conciliação entre família e trabalho, concentra-se no setor privado. Neste sentido Guerreiro (2000) refere que em certos cenários existe uma articulação com a ideia de responsabilidade social e em outros os agentes empregadores limitam-se a cumprir os preceitos legislativos de não discriminação. As tensões geradas na iniciativa privada fazem colidir os interesses da competitividade e lucro com os do tempo que os trabalhadores pretendem dedicar à família. O desafio é ainda maior em tempo de recessão. A conciliação entre os deveres familiares e obrigações profissionais não pode continuar a ser entendida como um assunto, exclusivamente, privado. Passar a ideologia para o contexto organizacional implica a análise de diferentes conceções de integração de igualdade de género. O diálogo social é potenciador de um processo transicional que retira o foco da linguagem neutral de género para a desvantagem posicional de género. Há um reconhecimento mútuo que homem e mulher têm direito aos mesmos recursos, ao mesmo empoderamento e à mesma visibilidade na esfera pública e na esfera privada, promovendo uma cultura mais consistente da responsabilidade social e, em última instância, a construção de uma sociedade mais coesa e progressista.

\section{Referências}

Arnot, M.; David, M. \& Weiner, G. (1999). Closing the Gender Gap: Postwar educational and social change. Cambridge: Polity Press.

Dornelas, António (coord.) et al (2011), Emprego, Contratação Colectiva de Trabalho e Protecção da Mobilidade Profissional em Portugal. Gabinete de Estratégia e Planeamento (GEP), Ministério do Trabalho e da Solidariedade Social (MTSS)

Durkheim, E. (1982). Rules of Sociological Method. London: Paperback.

Dworkin, R. (1985). A Matter of Principle. London: Clarendon Press.

Eurydice (2009). Diferenças de género nos resultados escolares. Estudo sobre medidas tomadas e situação actual na Europa. Bruxelas: Eurydice.

Fineman, M. A.; Zinsstag, E. (2013). Feminist Perspectives on Transitional Justice. Series on Transitional Justice, V. 13. Cambridge: Intersentia.

Fisher, M. (2011). Transitional Justice and Reconciliation. Em Austin, B., Fisher M., Giessmann J. (eds.) Advancing Conflict Transformation. The Berghof Handbook II. Opladen/Framington Hills: Barbara Budrich Publishers.
Frasier, N. (2002). A Justiça Social na Globalização: Redistribuição, reconhecimento e participação. Revista Crítica de Ciências Socias, 63, Outubro. (pp. 7-20).

Friedman, S. and Greenhaus, J. (2000). Work and Family-Allies or Enemies? Oxford: University Press.

Guerreiro, M. Dores (1998). A conciliação entre trabalho e vida familiar em Portugal. Em M. Dores Guerreiro (org.), Trabalho, família e gerações. Lisboa: CIES/ISCTE. (pp. 33-38).

Guerreiro, M. Dores e Perista, H. (1999). Trabalho $e$ Família. Em Inquérito à Ocupação do Tempo, Lisboa: Instituto Nacional de Estatística.

Guerreiro, M. D. (2010). As Políticas de Conciliação Trabalho-Família como Factor de Competitividade em Tempos de Crise. Vantagens Competitivas da Igualdade. CIES. Lisboa: ISCTE, IUL.

Guerreiro, M. D.; Pereira, I. (2006). Responsabilidade Social das Empresas, Igualdade e Conciliação Trabalho-Família: Experiências do Prémio Igualdade é Qualidade. Colecção Estudos 5. Lisboa: Comissão para a Igualdade no Trabalho e no Emprego. (p.8).

Habermas, J. (1998). Between Facts and Norms: Contributions to a Discourse Theory of Law and Democracy. London: Paperback.

Humm, M. (1989). The dictionary of feminist theory. Hemel Hemstead, UK: Harvester Wheatsheaf.

McGlynn, C. (2000). Ideologies of Motherhood in European Community Sex Equality Law, European Law Journal, Vol. 6 (1).

Neimanis, A. (2001). Gender mainstreaming in practice: A handbook. UNDP Regional Gender Programme of the United Nations. Development Programme's Regional Bureau for Europe and the CIS (UNDP RBEC). New York: UNDP.

Nussbaum, M. (2000). Women's Capabilites and Social Justice. Journal of Human Development, Vol I, no 2.

Paechter, C. (2000). Changing school subjects: Power, gender and the currículo. Buckingham: Open University Press.

V Plano Nacional para a Igualdade de Género, Cidadania e Não-Discriminação 2014-2017, Resolução do Conselho de Ministros n ${ }^{\circ} 103 / 2013$, publicado no DR, $1^{\circ}$ Série, $n^{\circ} 253$ de 31 de Dezembro.

Sammons, P. (1995). Gender, ethnic and socio-economic differences in attainment and progress: A longitudinal analysis of students achievement over 9 years. British Educational Research Journal. 21 (4) .

Rawls, J. (1993). Uma teoria da justiça. Lisboa: Fundamentos.

Villalba, C. S. (2011). Transitional Justice: Key Concepts, Processes and Challenges. Institute for Democracy \& Conflict Resolution. University of Essex Knowledge Gateway.

Walby, S. (2002). Gender and the New Economy: Regulation or deregulation? School of Sociology and Social Policy. Presented at ESCR seminar "Work, life and time in the new economy”. Leeds. UK.

\section{Agradecimentos}

Os meus agradecimentos ao Prof. Doutor Ribeiro Alves que me autorizou ao Congresso onde nasceu a ideia deste 
artigo. À minha Coordenadora Maria Nascimento Mateus pela constante disponibilidade. À minha colega de gabinete, Cristina Mesquita que me empurrou para esta iniciativa.

Ao meu filho que me confronta, diariamente, com a realidade de pertencermos a géneros diferentes. 